\title{
Branchial Ventilation Rates of Cataleptic Goldfish (Carassius auratus) and the Effects of Light and Electric Shock'
}

\author{
ALLEN VINEGAR \\ Mental Health Research Institute, and Department of Zoology, University of Michigan, Ann Arbor, \\ Michigan 48104, U.S.A. \\ AND \\ ROGER E. DAVIS \\ Mental Health Research Institute, and Department of Psychology, University of Michigan, Ann Arbor, \\ Michigan 48104, U.S.A.
}

(Received 3 July 1971)

\begin{abstract}
VINEGAR, A. AND R. E. DAVIS. Branchial ventilation rates of cataleptic goldfish (Carassius auratus) and the effects of light and electric shock. Physiol. Behav. 8 (3) 417-420, 1972.-Inverted, cataleptic goldfish showed an increase in ventilation rate over a $20 \mathrm{~min}$ period. The time-dependent increase in respiratory movement was initially suppressed when a $10 \mathrm{sec}$ light or a $0.1 \mathrm{sec}$ shock was presented at $1.5 \mathrm{~min}$ intervals. Contingent presentation of the light and shock, in a classical conditioning paradigm, resulted in reduced ventilation rates during the session. Physiological changes accompanying conditioning may thus alter the cataleptic state.
\end{abstract}

Catalepsy Branchial ventilation Classical conditioning Goldfish

DAVIS AND Holmes [3] reported that ECS can produce retrograde amnesia of classically conditioned inhibition of ventilation rates (opercula beats) in cataleptic goldfish. Prior experiments in noncataleptic fish showed that ECS can induce amnesia of an active avoidance response [1, 2]. That ECS can block retention of automatic and behavioral responses suggested that both types of responses could be mediated by common memory processes.

The use of catalepsy (animal hypnosis, tonic immobility) as a state in which to obtain conditioning for memory studies might be questioned because catalepsy is an unknown variable in the experiment. The available evidence regarding the occurrence of time-dependent changes in autonomic rhythms during catalepsy is largely non-quantitative and controversial. Ratner's [7] recent review reveals that breathing and heart rate are reported to increase, decrease, or remain unchanged in catalepsy.

The possible influence of external stimuli on autonomic rhythms in the immobile, manifestly unresponsive, individual also has not been extensively studied. Successful classical conditioning of respiratory [3] and cardiac [4] changes indicates that some external stimuli can be perceived in the cataleptic state. The present study was to determine the time course of changes in the periodicity of ventilation of goldfish in catalepsy, and the changes which are induced by the contingent and noncontingent presentation of light and electric shock stimuli.

\section{Fish}

METHOD

Common goldfish, Carassius auratus, $6-8 \mathrm{~cm}$ in body length, were obtained from Ozark Fisheries, Stoutland, Missouri. The fish were housed in large stock tanks for one to several weeks and just prior to experimentation placed in separate, clear plastic home tanks containing 1.51 of water. Water temperatures varied irregularly between 19 and $21 \mathrm{C}$ on different days. The animals received constant illumination and were never fed in the laboratory.

\section{Catalepsy}

Catalepsy was induced by quickly inverting the fish and placing it in a V-shaped groove in a block of soft polyurethane foam. The foam block was attached to the bottom of a small clear plastic tank. The tank was filled with water to a depth of $3 \mathrm{~cm}$ over the surface of the block. The water fully covered

\footnotetext{
${ }^{1}$ Supported by PHS Research Development Award K2-MH-22183 to R.E.D. from the National Institutes of Mental Health. Reprints can be obtained from R. E. Davis.
} 
the immobilized fish which lay with the ventral half of its body exposed above the block. The tank was continuously flushed with dechlorinated, tempered tap water $(20 \mathrm{C})$ at approximately $300 \mathrm{ml} / \mathrm{min}$.

Fish which resisted the inversion treatment were given gentle, rhythmic strokes with the experimenter's finger tips, in the area of the branchiostegal rays and anterior abdomen, to induce the trance. The immobile fish was then covered with a small, weighted block of foam which held the fish snugly in place but left its head and tail exposed. Fish could wiggle out of the foam groove [3].

Opercular movements were detected by two 20 gauge, silvered copper, wire electrodes placed near the sides of the head just posterior to the eyes. The opening and closing of the fish's opercula produced rhythmic changes in voltages at the tips of the electrodes. These voltage changes were recorded with a Grass Model III polygraph.

\section{Stimulus Presentation}

Red light from two 12 V Sylvania PSB lamps with red lens caps was presented for $10 \mathrm{sec}$. The lamps were placed $5 \mathrm{~cm}$ above the water and $5 \mathrm{~cm}$ to either side of the fish's head. They were directed downward at an angle of $45^{\circ}$ to provide even, direct illumination to the fish's eyes about $1 \mathrm{~cm}$ beneath the water surface.

The shock was a $100 \mathrm{msec}$ pulse of $5 \mathrm{~mA}, 60 \mathrm{~Hz}$ current. The shock was administered between two lead electrodes lying $1 \mathrm{~cm}$ from either side of the fish posterior to the pectoral fins. The electrodes were held in slits in the foam block on either side of the V-shaped groove. The polygraph electrodes were automatically disconnected for $500 \mathrm{msec}$ to deliver the shock.

\section{Protocol}

The fish were divided into 5 groups of 6 individuals. Fish were placed in catalepsy for about $22 \mathrm{~min}$. Fifteen stimulus presentations (trials), consisting of the light or the shock, or the light plus the shock, or neither, were given starting a minute after initiation of catalepsy (Table 1). Groups 2, 3, and 4 received trials at $1.5 \mathrm{~min}$ intervals and data was recorded in every trial. For group 5, trials were administered at variable intervals which averaged $1.5 \mathrm{~min}$, and data was recorded only in Trials $1,5,10$ and 15, which was the previously described procedure [3]. When light and shock were presented contingently, the shock occurred at the end of the $10 \mathrm{sec}$ light. Ventilation rates were determined for 3 consecutive $10 \mathrm{sec}$ periods in a trial (Table 1). Period A was scheduled immediately before the light stimulus, or at a corresponding time in the session for Groups 1 and 3 which did not receive the light. Period $\mathrm{B}$ coincided with the light, and period $\mathrm{C}$ occurred immediately following the shock or at corresponding times in the session.

The changes in ventilation in response to the light or the shock is expressed as a suppression ratio. The ratio for the response to light was calculated as the opercular beats in period $\mathrm{B}$ divided by the sum of the beats in $\mathrm{B}$ and $\mathrm{A}$. A ratio of 0.5 signifies no response. The ratio for the response to shock was $\mathrm{C} / \mathrm{B}+\mathrm{C}$.

\section{RESULTS}

Group 1 showed a significant increase in ventilation rate with time in catalepsy (A period; Fig. 1) Groups 2 and 3 also showed increased ventilation over the 15 trials but the mean rate was less than that in Group 1. Repeated presentations of either the light or the shock thus reduced the rate of ventilation. In Group 4, the period A rate decreased over the first few trials and then remained unchanged.

Presentation of light alone (Group 2) resulted in increased ventilation rates in periods $A, B$ and $C$ (Figs 1-3). The increase appeared after 5 trials, not immediately, suggesting that the light had an unconditioned inhibitory effect which subsequently disappeared. This impression is supported by the suppression ratio for the response to light $(B / A+B)$. The ratio was initially low and then approached 0.5 in several trials (Fig. 4).

Presentation of shock alone (Group 3) resulted in a decreased ventilation rate in periods $A$ and $B$ over the first few trials but in subsequent trials the rate increased. The mean suppression ratio of the response to shock $(\mathrm{C} / \mathrm{B}+\mathrm{C})$ was 0.427 and it did not vary significantly over the 15 trials $(\mathrm{F}=0.92 ; d f=14,70)$. The difference in rate in the $\mathrm{C}$ period between Group 2 and 3 (Fig. 3 ) is not significant. A

TABLE 1

TREATMENT OF THE DifFERENT Groups

\begin{tabular}{|c|c|c|c|c|c|c|}
\hline \multirow[t]{2}{*}{ Group } & \multirow[t]{2}{*}{$\begin{array}{c}\text { Stimuli } \\
\text { Presented }\end{array}$} & \multirow[t]{2}{*}{$\mathbf{N}$} & \multirow{2}{*}{$\begin{array}{c}\text { Intertrial } \\
\text { Interval } \\
\text { (min) }\end{array}$} & \multicolumn{3}{|c|}{$\begin{array}{c}\text { Consecutive Periods of Measurement } \\
\text { in Each Trial }\end{array}$} \\
\hline & & & & A & B & $\mathrm{C}$ \\
\hline 1 & none & 6 & $1-1 / 2$ & + & & \\
\hline 2 & light & 6 & $1-1 / 2$ & + & + & + \\
\hline 3 & shock & 6 & $1-1 / 2$ & + & + & + \\
\hline 4 & $\begin{array}{l}\text { light, } \\
\text { shock }\end{array}$ & 6 & $1-1 / 2$ & + & + & + \\
\hline 5 & $\begin{array}{l}\text { light, } \\
\text { shock }\end{array}$ & 6 & $1-1 / 2 \dagger$ & $+^{*}$ & $+^{*}$ & \\
\hline
\end{tabular}

* Respiratory beats recorded only in trials $1,5,10$ and 15 .

$\dagger$ Average for the 15 trials; the intervals ranged from $45 \mathrm{sec}$ to $2 \mathrm{~min} 10 \mathrm{sec}$. The same

schedule used in the previously reported conditioning procedure [3]. 


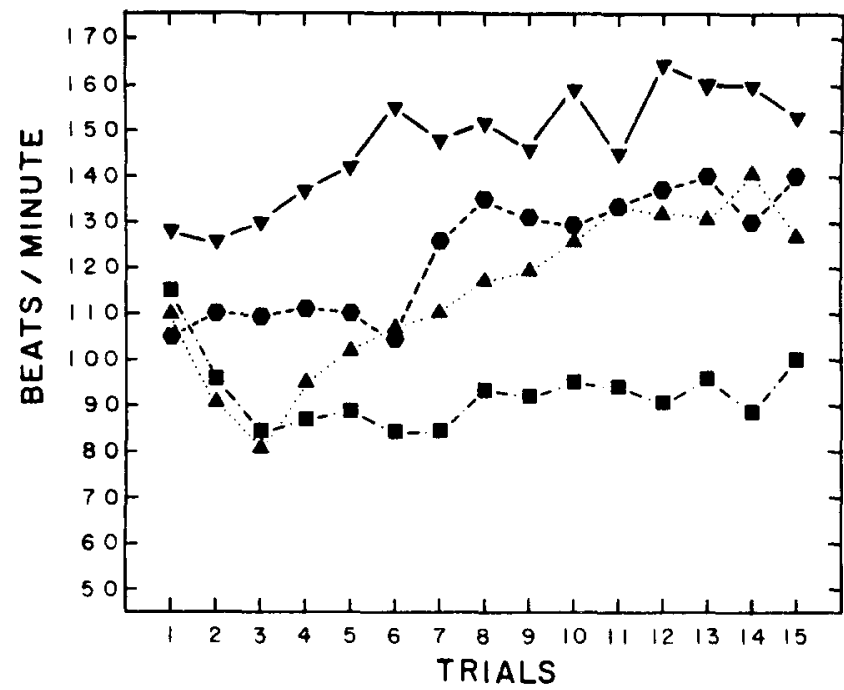

FIG. 1. Ventilation rates for period A: Group $1(\boldsymbol{\nabla})$, Group 2 (hexagon), Group $3(\boldsymbol{\Delta})$, Group $4(\boldsymbol{U})$. Analysis of variance: Groups $\mathrm{F}=6.4 ; d f=3,15 ; p<0.01$. Trials $\mathrm{F}=13.0 ; d f=$ 14,$70 ; \quad p<0.01$. Groups $\times$ Trials $\mathrm{F}=2.3 ; \quad d f=42,240$; $p<0.01$.

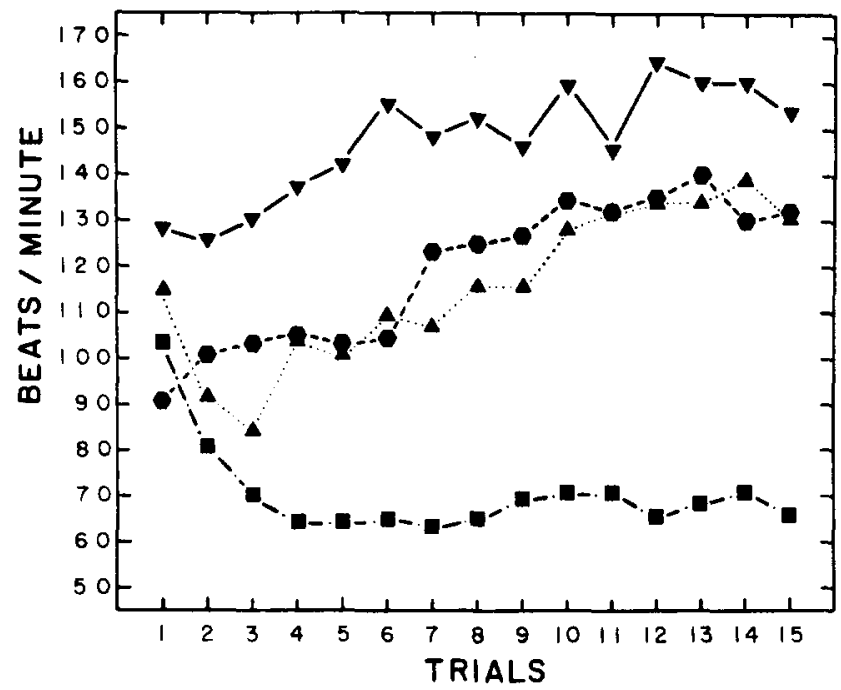

FIG. 2. Ventilation rates for period B: Group $1(\boldsymbol{\nabla})$, Group 2 (hexagon), Group $3(\mathbf{A})$, Group $4(\mathbf{a})$. Analysis of variance: Groups $\mathrm{F}=12.4 ; d f=2,10 ; p<0.01$. Trials $\mathrm{F}=8.0 ; d f=$ 14,$70 ; \quad p<0.01$. Groups $\times$ Trials $F=4.1 ; \quad d f=28,140$; $p<0.01$. Group 1 is not included in the analysis.

fish in Group 3 consistently showed a marked increase in ventilation in response to the shock, instead of a decrease. The data for this unusual individual confounds the test of group differences in the $\mathrm{C}$ period.

The results for Group 4 revealed that the ventilation rate in period $B$ initially decreased then leveled off (Fig. 2) paralleling the changes seen in period $\mathrm{A}$ (Fig. 1). The suppression ratio for the response of Group 4 to light $(B / A+B)$ decreased over the 15 trials $(\mathrm{F}=2.0 ; d f=14,70 ; p<0.05)$ as shown in Fig. 4. A decrease in ratio was also shown by Group 5 (Fig. 4) which received the light plus shock trials at varying intervals $(\mathrm{F}=22.7 ; d f=3,15 ; p<0.01)$. The suppression ratios of Groups 4 and 5 in trials $1,5,10$ and 15 were statistically equivalent $(\mathrm{F}<1)$.

\section{DISCUSSION}

The present results show that the ventilation rate in period A increases with time in catalepsy. The increase in the ventilation can be suppressed by repeated presentation of light or shock. After several trials, however, the inhibitory effect of

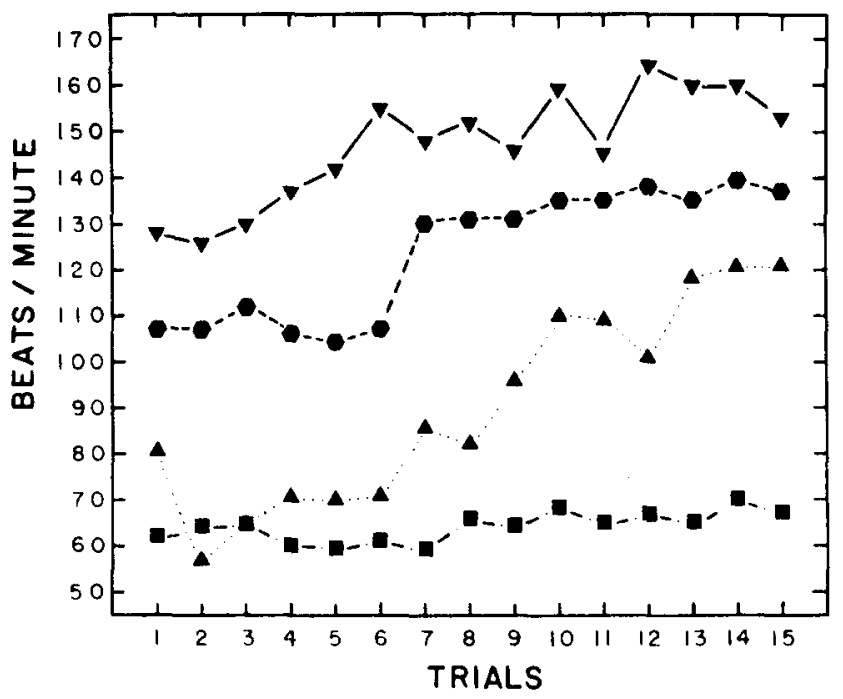

FIG. 3. Ventilation rates for period C: Group 2 (hexagon), Group $3(\Delta)$, Group $4(\square)$. Analysis of variance: Groups $\mathrm{F}=10.9 ; \quad d f=2,10 ; p<0.01$. Trials $\mathrm{F}=8.9 ; \quad d f=14,70 ;$ $p<0.01$. Groups $\times$ Trials $F=2.2 ; d f=28,140 ; \quad p<0.01$. Group 1 is not included in the analysis.

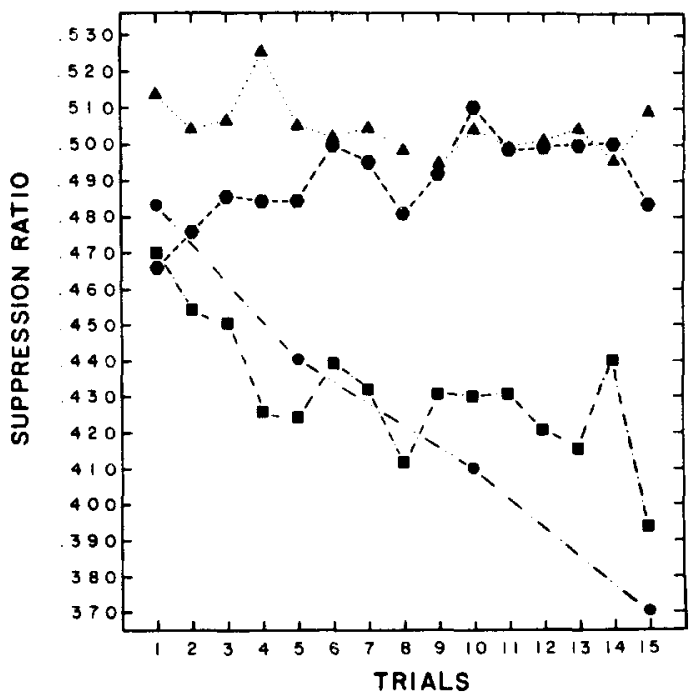

FIG. 4. Suppression ratios of the response to light, period $B / A+B$, of Group 2 (hexagon), $3(A), 4(v)$, and $5(\bullet)$. Group 3 did not receive the light in period $B$. Thus the curve reflects presumably random changes in ventilation rate from period $A$ to period $B$. 
these stimuli disappears or is greatly reduced. The shock alone elicits an immediate, presumably unconditioned inhibition of ventilation. When light and shock are presented together, after several trials the light increasingly inhibits respiratory movements prior to the onset of the shock. The acquired inhibitory effect of the light is assumed to reflect a conditioned response to the shock.

The time-dependent increase in ventilation shown by Groups 1, 2 and 3 (Fig. 1) cannot readily be attributed to changes in the external environment. Increased water temperature or concentration of carbon dioxide, for example might induce faster ventilation. But such changes are presumed to be eliminated or greatly reduced by the continuous flow of fresh water in the experimental tank. The increase in ventilation rate appears to be a correlate of catalepsy in goldfish.

The results for Groups 2 and 3 show that the time-dependent increase in ventilation rate (period A) occurred despite the repeated presentation of either the light or the shock. Group 4 , on the other hand, showed a decrease in rate with time in catalepsy indicating that the conditioning paradigm had an overall suppressive effect. This result may or may not indicate a basic, independent effect of the conditioning process on the cataleptic state. The decreased ventilation might represent a summation of the suppression effects of the conditioned light stimulus and the immediately ensuing shock stimulus. The resultant greater inhibition at the end of each trial might require a longer intertrial interval for recovery to a rate which would otherwise be reached.

The use of ventilation rate as an index of autonomic conditioning in goldfish has been reported by Fay [5], Otis, Cerf and Thomas [6] and Roots and Prosser [8]. In these experiments, fish were held firmly in an upright position. Conditioning in upright fish can be obtained within 10-20 trials in a single session. Our results would suggest that the inversion of fish neither impedes nor facilitates the process. The occurrence of time-dependent changes in ventilation rate in fish which are held right side up remains to be determined. Possibly, the firm restraint needed to hold still an upright fish is a sufficient stimulus to induce catalepsy [3]. A method of registering respiratory movements in unrestrained fish has recently been described [9]. Thus it may be feasible to assess the respiratory changes which occur during a condition session in freely moving, noncataleptic individuals. An independent physiological correlate of catalepsy would facilitate investigations of this poorly understood behavior.

\section{REFERENCES}

1. Davis, R. E., P. J. Bright and B. W. Agranoff. Effect of ECS and puromycin on memory in fish. J. comp. physiol. Psychol. 60: 162-166, 1965.

2. Davis, R. E. and M. E. Hirtzel. Environmental control of ECS-produced amnesia in goldfish. Physiol. Behav. 5: 1089-1092 1970.

3. Davis, R. E. and P. A. Holmes. ECS-produced retrograde amnesia of conditioned inhibition of respiration in cataleptic goldfish. Physiol. Behav. 7: 11-14, 1971.

4. Draper, D. C. and W. R. Klemm. Behavioral responses associated with animal hypnosis. Psychol. Rec. 17: 13-21, 1971.

5. Fay, R. R. Auditory frequency generalization in the goldfish (Carassius auratus). J. exp. Analysis Behav. 14: 353-360, 1970.
6. Otis, L. S., J. A. Cerf and G. J. Thomas. Conditioned inhibition of respiratory and heart rate in the goldfish. Science 126: 263-264, 1957.

7. Ratner, S. C. Comparative aspects of hypnosis. In: Handbook of Clinical and Experimental Hypnosis, edited by J. E. Gordon. New York: MacMillan, 1967, pp. 550-587.

8. Roots, B. I. and C. L. Prosser. Temperature acclimation and the nervous system in fish. $J$. exp. Biol. 39: 617-629, 1962.

9. Spoor, W. A., T. W. Neiheisel, and R. A. Drummond. An electrode chamber for recording respiratory and other movements of free-swimming animals. Trans. Am. Fish. Soc. 100: 22-28, 1971. 